\title{
THE CARDIAC OUTPUT IN PATIENTS WITH ARTERIOVENOUS FISTULAS ${ }^{1}$
}

\author{
BY JAMES V. WARREN, JOHN L. NICKERSON, AND DANIEL C. ELKIN \\ (From the Departments of Medicine and Surgery, Emory University School of Medicine, Atlanta. \\ Georgia; The Department of Physiology of the College of Physicians and Surgeons, \\ Columbia University, New York; and the Vascular Surgery Center, Ashford \\ General Hospital, White Sulphur Springs, West Virginia)
}

(Submitted for publication October 21, 1950; accepted, November 20, 1950)

The study of arteriovenous fistulas, and the alterations in local and systemic circulation which they produce, has been a means of not only understanding this particular lesion better, but of extending our knowledge of many other more common circulatory phenomena. In peacetime, investigations have been conducted on the relatively rare clinical cases and on animals with fistulas produced in the laboratory. The recent war, with its many vascular injuries, presented an unusual opportunity to study the circulatory alterations in patients with arteriovenous fistulas. This and succeeding reports deal with observations on a large group of patients treated at Ashford General Hospital.

The clinical manifestations exhibited by patients with an arteriovenous fistula have been described elsewhere $(1,2)$. It is generally recognized that these patients may develop congestive heart failure. There has been controversy, however, regarding the mechanism producing the circulatory failure. Some have ascribed it to greatly increased demands on the heart, others to diminution of coronary blood flow secondary to the lowered mean arterial pressure (3). Since a knowledge of the output of the heart is so important in defining the mechanism of the altered circulatory dynamics in these patients, we have measured the cardiac output as part of a general study of the circulation in patients with arteriovenous fistulas.

In 1923 Lewis and Drury (4) reported the results of their studies of arteriovenous fistulas in both man and the experimental animal. In the latter, using a glass cardiometer to enclose the heart, they found an increase in cardiac output, in

1 The work described in the paper was done under a contract, recommended by the Committee on Medical Research, between the Office of Scientific Research and Development and the Emory University School of Medicine, Atlanta, Georgia. some instances, when the fistula was open. In the animals with an elevated cardiac output they also noticed an increased central venous pressure. Because the venous pressure was found to be normal in their human cases, they assumed that the cardiac output was normal. No actual measurements on humans were reported. Harrison, Dock and Holman (5) in 1924, using the direct Fick technique, reported that the cardiac output was elevated in their animals with experimental arteriovenous fistulas. Since then, several additional studies in experimental animals have confirmed the earlier observations that the basal cardiac output may be elevated by the creation of an arteriovenous fistula $(3,6-8)$. On the other hand, the relatively few clinical observations made on patients with arteriovenous fistulas led to less definitive conclusions; in most instances an increased cardiac output was found (9-14). These data have been summarized in two recent reports $(3,14)$. It may be that the foreign gas methods, often used in McMichael clinical studies, were invalidated by the abnormal circulatory dynamics present in these patients. Insofar as we are aware, there is no study reported of the cardiac output in a large group of patients observed before and after removal of an arteriovenous fistula.

\section{METHODS}

The cardiac output was determined by means of the low frequency, critically damped ballistocardiograph (15, 16) which measures the output by the ballistic recoil of the body with each heart beat.

To verify the validity of the measurements by the ballistocardiograph in the presence of arteriovenous fistulas or large areas of reactive hyperemia (in reality a temporary arteriovenous fistula) comparative studies by the direct Fick technique were made (16-19). A satisfactory correlation between the two methods was demonstrated. We believe, therefore, that, under the conditions of the present study, the ballistocardiographic method is a useful and valid one. 
To facilitate comparison of individuals of various sizes, the cardiac index (the output of the heart in liters per minute per square meter of body surface) was used in recording our observations. All determinations were made on subjects three hours or more after they had eaten, and after they had relaxed for at least 15 minutes on the ballistocardiograph table. The arterial pressure was obtained with an ordinary mercury manometer by the auscultatory method. In patients with a fistula sufficiently distal on an extremity so that occlusion could be accomplished by inflation of a blood pressure cuff, observations were made before and during the occlusion of the fistula. These studies are reported separately (20). The transverse diameter of the heart as measured from a teleoroentgenogram was used as an index of changes in heart size. The blood volume was measured by means of the blue dye T-1824 (21).

\section{RESULTS}

Forty-seven patients with arteriovenous fistulas were studied at least once before and after operation. Many had a cardiac output determination on several occasions. All the patients were presumably normal prior to their injury resulting in the establishment of the arteriovenous fistula. All except on were men. The time between the injury causing the fistula and the operative repair varied from two months to slightly over two years. No patient had evidence of frank congestive heart failure. All the patients had definite local signs of the fistula, such as thrill or murmur. In all, the fistula was demonstrated and successfully removed at operation. In none was there evidence of recurrence, nor was the postoperative course seriously complicated.

The results of the cardiac output determinations and related observations are recorded in Table I. We have considered the value, or average of several values, obtained 10 days or more after removal of the fistula, as the normal resting output for each patient. Using this normal value for comparison, the preoperative cardiac outputs are seen to range from 127 per cent above to 21 per cent below the normal resting cardiac output (Figure 1). Our experience has been that in normal subjects a variation of as much as 25 per cent above or below a value selected as the resting cardiac output may be expected on repeated measurements on different days.

As can be seen from Table I, the alteration in cardiac output is predominantly the result of change in stroke volume rather than pulse rate.

TABLE I

Observations on 47 patients with arteriovenous fistulas before and after operation

\begin{tabular}{|c|c|c|c|c|c|c|c|}
\hline $\begin{array}{l}\text { Location of fistula } \\
\text { and number of } \\
\text { patients in group }\end{array}$ & $\begin{array}{l}\text { Duration } \\
\text { of fistula }\end{array}$ & $\begin{array}{c}\text { Time of } \\
\text { observation }\end{array}$ & Pulse rate & Stroke volume & Cardiac index & $\begin{array}{l}\text { Change in } \\
\text { heart size }\end{array}$ & $\begin{array}{c}\text { Change in } \\
\text { blood volume }\end{array}$ \\
\hline $\begin{array}{c}\text { Carotid } \\
\text { (5) }\end{array}$ & $\begin{array}{c}\text { months } \\
4.9\end{array}$ & $\begin{array}{c}\text { days before and } \\
\text { after operation } \\
6 \text { before } \\
14 \text { after }\end{array}$ & $\begin{array}{c}\text { beats per min. } \\
73 \\
70\end{array}$ & $\begin{array}{l}c c . \\
116 \\
80\end{array}$ & $\begin{array}{c}\text { liters per min. } \\
\text { per sq. m. } \\
4.5 \\
3.7\end{array}$ & $\begin{array}{c}c m \\
-0.5\end{array}$ & $\begin{array}{c}\text { cc. per sq. } m . \\
-440\end{array}$ \\
\hline $\begin{array}{l}\text { Vertebral } \\
(1)\end{array}$ & 8 & $\begin{array}{l}1 \text { before } \\
18 \text { after }\end{array}$ & $\begin{array}{l}81 \\
78\end{array}$ & $\begin{array}{r}114 \\
93\end{array}$ & $\begin{array}{l}4.5 \\
3.7\end{array}$ & -0.2 & \\
\hline $\begin{array}{l}\text { Subclavian } \\
(3)\end{array}$ & 3.3 & $\begin{array}{l}19 \text { before } \\
4 \text { after }\end{array}$ & $\begin{array}{l}71 \\
71\end{array}$ & $\begin{array}{r}114 \\
80\end{array}$ & $\begin{array}{l}4.0 \\
2.8\end{array}$ & +1.2 & -155 \\
\hline $\begin{array}{l}\text { Axillary } \\
(3)\end{array}$ & 11.3 & $\begin{array}{l}13 \text { before } \\
14 \text { after }\end{array}$ & $\begin{array}{l}65 \\
78\end{array}$ & $\begin{array}{l}145 \\
104\end{array}$ & $\begin{array}{l}4.9 \\
4.5\end{array}$ & & -200 \\
\hline $\begin{array}{l}\text { Brachial } \\
\text { (4) }\end{array}$ & 5 & $\begin{array}{l}5 \text { before } \\
14 \text { after }\end{array}$ & $\begin{array}{l}74 \\
66\end{array}$ & $\begin{array}{r}122 \\
94\end{array}$ & $\begin{array}{l}4.3 \\
3.9\end{array}$ & -0.2 & +40 \\
\hline $\begin{array}{l}\text { Iliac } \\
(3)\end{array}$ & 7.2 & $\begin{array}{l}15 \text { before } \\
20 \text { after }\end{array}$ & $\begin{array}{l}84 \\
72\end{array}$ & $\begin{array}{r}115 \\
80\end{array}$ & $\begin{array}{l}7.1 \\
3.2\end{array}$ & -0.6 & -453 \\
\hline $\begin{array}{c}\text { Femoral } \\
(12)\end{array}$ & 5 & $\begin{array}{l}8 \text { before } \\
16 \text { after }\end{array}$ & $\begin{array}{l}82 \\
73\end{array}$ & $\begin{array}{r}115 \\
94\end{array}$ & $\begin{array}{l}6.0 \\
3.9\end{array}$ & -1.2 & -304 \\
\hline $\begin{array}{l}\text { Popliteal } \\
(5)\end{array}$ & 9.6 & $\begin{array}{l}9 \text { before } \\
21 \text { after }\end{array}$ & $\begin{array}{l}66 \\
65\end{array}$ & $\begin{array}{l}134 \\
103\end{array}$ & $\begin{array}{l}4.8 \\
3.6\end{array}$ & -0.6 & -210 \\
\hline $\begin{array}{r}\text { Tibial } \\
(11)\end{array}$ & 8.2 & $\begin{array}{l}6 \text { before } \\
23 \text { after }\end{array}$ & $\begin{array}{l}67 \\
70\end{array}$ & $\begin{array}{r}107 \\
94\end{array}$ & $\begin{array}{l}4.0 \\
3.5\end{array}$ & -0.2 & -123 \\
\hline
\end{tabular}




\section{EFFECT OF A-V FISTULA ON CARDIAC OUTPUT}

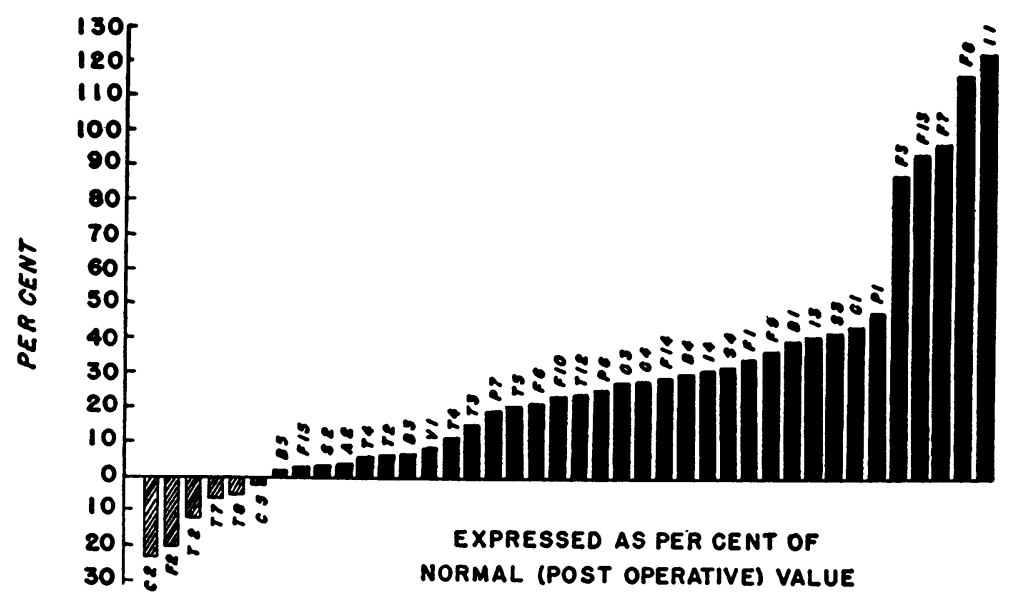

Fig. 1. The Effect of Removal of an Arteriovenous Fistula on the Cardiac Output

In only seven patients with the fistula intact was the basal pulse rate above 85 beats per minute. In four of these the fistula involved the femoral vessel ; in two, the iliac; and in one, the subclavian. The cardiac output in this group of patients averaged 82 per cent above the postoperative level and ranged from 32 per cent to 127 per cent.

The arterial blood pressure showed little variation from the preoperative to postoperative period. In general, if change occurred there was a tendency toward diminution of the pulse pressure postoperatively, due predominantly to an elevation of the diastolic pressure.

In those instances where satisfactory measurements were obtained, the changes in transverse diameter of the heart and blood volume are recorded. These are discussed in detail elsewhere (21).

\section{DISCUSSION}

Our patients were apparently healthy young adults before injury. Although the person to person variability in cardiac output is large, our study could have been made using an average normal value for comparison with the value found in the presence of the fistula. We were fortunate, however, in that our patients returned to a normal state after operation without evidence of residual abnormality in the circulation. The postoperative cardiac index varied considerably from patient to patient, but the range was similar to that found in a comparable group of normal subjects studied by the catheter method (22). Therefore, we have utilized the value obtained postoperatively for each individual as his normal and have used this value as the basis of estimating the load placed on the heart by the fistula.

The resting cardiac output with the fistula intact varied from 21 per cent below the postoperative value to 127 per cent above. A variation of 25 per cent above and below the postoperative value might be expected in any group of patients so studied and, therefore, could not be attributed to the effect of the fistula. In 22 , or 47 per cent, of the patients, the change in cardiac output fell within this \pm 25 per cent range. In these patients the fistula was not large enough to produce a significant change in cardiac output. In all of the other patients (25, or 53 per cent), the cardiac output with the fistula open was more than 25 per cent greater than the postoperative cardiac output, the values ranging from 25 per cent to 127 per cent above the normal output. We believe that these increases of more than 25 per cent in cardiac output are significant. This indicates that about onehalf of our patients with arteriovenous fistula had a significantly elevated cardiac output as measured under basal conditions.

The increased cardiac output was primarily the result of an increase in stroke volume. The postoperative basal pulse rate was above 85 beats per minute in only seven patients. In these patients, all with clinical evidences of a large fistula, the cardiac output was markedly elevated, averaging 82 per cent above the postoperative level. 
A clinical or pathological determination of the functional size of the fistula was difficult. It may be that the increase in cardiac output is the best index of the load placed on the circulation by the fistula (13). Such signs as the size of the vessel involved or the intensity of the thrill or murmur were not entirely reliable in predicting the increase in cardiac output. In general, it appeared that those patients with clinical evidence suggestive of a large fistula or one located in a large vessel had a markedly elevated cardiac output. A review of the cases studied shows that while all of those patients with a marked elevation of cardiac output had fistulas involving relatively large vessels, there appeared to be no more specific relationship. In other words, a fistula of the femoral vessel might cause either a small or a large increase in cardiac output. On the contrary, a fistula fed by a small vessel, because of the limited arterial inflow, caused at most only a small increase in cardiac output.

A correlation of the age of the fistula with the increase in cardiac output showed that most patients with a large increase had fistulas of relatively short duration; those with small increases, in many instances, had fistulas of much longer duration. However, these findings are probably due to the fact that while small fistulas may have escaped notice for a long time, the larger ones were diagnosed and referred to our hospital with greater rapidity.

It is well recognized, however, that patients with an arteriovenous fistula may have cardiac enlargement, as evidenced by an increased transverse diameter of the heart in the teleoroentgenogram (23). This change is reversible, and the heart size returns to normal after operative removal of the fistula. We have attempted to correlate the change in transverse diameter of the heart following operation with the degree of increase in cardiac output. The correlation coefficient between the variables is 0.12 which indicates a poor correlation.

The effect of an arteriovenous fistula upon blood volume has been discussed in an accompanying paper (21). Although there is no direct correlation between the increase in blood volume and the increase in cardiac output, there is, however, an indication that the blood volume tends to be increased in those patients with an elevated cardiac output and with clinical evidences of a large fistula. The effects of temporary occlusion of the fistula upon pulse rate, stroke volume, and cardiac output are likewise discussed separately (20).
From these studies it appears that many, but not all, patients with an arteriovenous fistula have a distinct elevation of the cardiac output above their normal level. It also appears that soon after the removal of the fistula there is a return of the output of the heart to an approximately normal value.

A complete explanation of the increased cardiac output in patients with an arteriovenous fistula is not yet possible. The usual explanation stresses the importance of the filling pressure of the ventricles, i.e., the pressure in the atria and the great veins. It has, however, been demonstrated in patients with arteriovenous fistula or with large areas of hyperemia (17) that a marked change in cardiac output can occur without the appearance of any change in atrial pressure. For this reason atrial pressure changes are not a significant aid in explaining the increased cardiac output.

The observation of a marked fall in peripheral resistance when the fistula is open and indication from the ballistocardiogram that upon opening and closing the fistula the changes in heart rate and stroke volume appear within the first few beats suggest that the changed cardiac output depends on some property of the peripheral vascular bed. This view is discussed more fully elsewhere (17, 20).

Although our studies did not reveal specific data on cardiac failure in patients with arteriovenous fistula, they indicated a similarity of this condition to that of patent ductus arteriosus, severe anemia, and thyrotoxicosis in which cardiac failure occurs when the output is distinctly above normal. Therefore, in patients with arteriovenous fistula, a low output of the heart would not necessarily indicate circulatory inadequacy. On the other hand, the resistance of the cardiovascular system to stress varies so greatly in individuals that cardiac failure would not necessarily develop in those patients with the highest output.

As Starr and Jonas (24) had pointed out regarding patients with thyrotoxicosis, it is possible that a normal cardiac output in the face of the increased demands would be suggestive of cardiac failure. The combination of a normal cardiac output and a large fistula might be more indicative of cardiac insufficiency than merely a large cardiac output would be. This may be another reason why the cardiac enlargement or the elevated blood volume cannot be directly correlated with the increase in cardiac output. 


\section{SUMMARY AND CONCLUSIONS}

A study of the cardiac output in 47 patients with arteriovenous fistulas was made by means of the low frequency critically damped ballistocardiograph before and after operative removal of the fistula. In 22 ( 47 per cent) of the patients there was a change of less than 25 per cent in the cardiac output in the presence of a fistula, when compared with the later normal values obtained for each patient after operative removal of the fistula. This change was not considered a significant one.

In 25 ( 53 per cent) of the patients with the fistula intact, there was elevation of the cardiac output of from 25 to 127 per cent above the postoperative (normal) level. Although, in general, these patients were the ones with clinical evidences of large fistulas, there was no striking correlation with the change in cardiac size, blood volume, or pulse rate, nor with duration of the fistula.

The evidence at hand indicates that the increased cardiac output is not due to an increase in filling pressure presented to the right side of the heart, but rather is related to change in the arterial tree.

Misses Maurine Giese and Margaret Steele gave valuable technical assistance.

\section{REFERENCES}

1. Holman, E., Arteriovenous Aneurysm; Abnormal Communications Between the Arterial and Venous Circulations. Macmillan Co., New York, 1937.

2. Elkin, D. C., and Warren, J. V., Arteriovenous fistulas: Their effect on the circulation. J.A.M.A., 1947, 134, 1524.

3. McGuire, J., Hauenstein, V., Stevens, C. D., and Sharrets, K. C., Effects of arteriovenous fistulae on the heart and circulation in Am. A. Advancement Sc., Blood, Heart and Circulation. Science Press, Washington, 1940, p. 213.

4. Lewis, T., and Drury, A. N., Observations relating to arteriovenous aneurysm; circulatory manifestations in clinical cases with particular reference to arterial phenomena of aortic regurgitation. Heart, 1923, 10, 301.

5. Harrison, T. R., Dock, W., and Holman, E., Experimental studies in arteriovenous fistulae: cardiac output. Heart, 1924, 11, 337.

6. Gibbon, J. H., Jr., and Churchill, E. D., Changes in pulmonary circulation induced by experimentally produced arteriovenous fistula. Arch. Surg., 1930, $21,1188$.

7. Gley, P., and Gomez, D. M., Le travail du coeur sous l'influence des anévrysmes artérioso-veineux. J. de physiol. et de path. gén., 1931, 29, 442.

8. Reid, M. R., and McGuire, J., Arteriovenous aneurysms. Ann. Surg., 1938, 108, 643.
9. Smith, C., Circulation in arteriovenous aneurysm; before and after operation. Arch. Int. Med., 1931, 48, 187.

10. Horton, B. T., Hemihypertrophy of extremities associated with congenital arteriovenous fistula. J.A.M.A., 1932, 98, 373.

11. Laplace, L. B., Observations on the effect of an arterio-venous fistula on the human circulation. Am. J. M. Sc., 1935, 189, 497.

12. Ellis, L. B., and Weiss, S., The local and systemic effects of arteriovenous fistula on the circulation of man. Am. Heart J., 1929, 5, 635.

13. Starr, I., Clinical studies with the ballistocardiograph: in congestive failure, on digitalis action, on changes in ballistic form, and certain acute experiments. Am. J. M. Sc., 1941, 202, 469.

14. Kennedy, J. A., and Burwell, C. S., Measurements of the circulation in a patient with multiple arteriovenous connections. Am. Heart J., 1944, 28, 133.

15. Nickerson, J. L., and Curtis, H. J., The design of the ballistocardiograph. Am. J. Physiol., 1944, 142, 1.

16. Nickerson, J. L., Warren, J. V., and Brannon, E. S., The cardiac output in man: studies with the low frequency, critically-damped ballistocardiograph, and the method of right atrial catheterization. J. Clin. Invest., 1947, 26, 1.

17. Stead, E. A., Jr., and Warren, J. V., Cardiac output in man; an analysis of the mechanisms varying the cardiac output based on recent clinical studies. Arch. Int. Med., 1947, 80, 237.

18. Cournand, A., Ranges, H. A., and Riley, R. L., Comparison of results of the normal ballistocardiogram and a direct Fick method in measuring the cardiac output in man. J. Clin. Invest., 1942, 21, 287.

19. Starr, I., Rawson, A. J., Schroeder, H. A., and Joseph, N. R., Studies on the estimation of the cardiac output in man, and of abnormalities in cardiac function, from the heart's recoil and the blood's impacts; the ballistocardiogram. Am. J. Physiol., $1939,127,1$.

20. Nickerson, J. L., Elkin, D. C., and Warren, J. V., The effect of temporary occlusion of arteriovenous fistulas on the heart rate, stroke volume, and cardiac output. J. Clin. Invest., 1951, 30, 215.

21. Warren, J. V., Elkin, D. C., and Nickerson, J. L., The blood volume in patients with arteriovenous fistulas. J. Clin. Invest., 1951, 30, 220.

22. Stead, E. A., Jr., Warren, J. V., Merrill, A. J., and Brannon, E. S., The cardiac output in male subjects as measured by the technique of right atrial catheterization. Normal values with observations on the effect of anxiety and tilting. J. Clin. Invest., $1945,24,326$.

23. Pendergrass, R. C., Cardiac changes in arteriovenous fistula. Am. J. Roentgenol., 1945, 53, 423.

24. Starr, I., and Jonas, L., Supernormal circulation in resting subjects (hyperkinemia) with a study of the relation of kinemic abnormalities to the basal metabolic rate. Arch. Int. Med., 1943, 71, 1. 